\title{
A Solidariedade COMO Fundamento PARA O Enfrentamento do Covid-19 NA União Europeia ${ }^{1}$
}

\author{
Solidarity as A BASIS fOR Confronting Covid-19 IN \\ THE EUROPEAN UNION
}

\section{LA SOLIDARIDAD COMO FUndAMENTO PARA ENFRENTAR el Covid-19 en la Unión Europea}

\author{
Jamile Bergamaschine Mata Diz* \\ Elizabeth Accioly Rodrigues Costa* \\ Alice Rocha da Silva ${ }^{* * *}$
}

\begin{abstract}
1 Introdução. 2 O processo decisório sobre o enfrentamento do COVID-19 dentro das competências europeias. 2.1 Princípios de regência da competência. 2.2. A definição da competência relacionada à política de saúde no contexto europeu. 3 O enfrentamento do COVID-19 a partir dos instrumentos preestabelecidos pelo sistema europeu. $3.1 \mathrm{O}$ mecanismo de proteção civil como catalizador de medidas comuns em caso de catástrofes. 3.2 Centro Europeu de Prevenção e Controle de Doenças. 3.3 Sistema de Alerta Rápido e Resposta (SARR). $4 \mathrm{O}$ dever de solidariedade previsto no tratado de funcionamento da união europeia e o COVID-19: há parâmetros de comparação entre "antes e depois”. 5 A possibilidade de novas medidas frente à especificidade do COVID-19 e o dever de solidariedade. 6 Conclusão. Referências.
\end{abstract}

\section{RESUMO}

Objetivo: $O$ presente artigo busca estabelecer como os procedimentos e normas estabelecidos pela União Europeia foram determinados diante da crise gerada pela

A autora Jamile Bergamaschine Mata Diz agradece à Coordenação de Aperfeiçoamento de Pessoal de Nível Superior - Brasil (CAPES) - Código de Financiamento 001, apoio para a realização da presente pesquisa no marco do Programa CAPES/PRINT (Edital 2018), modalidade Professor visitante sênior exterior/Instituto Europeu da Faculdade de Direito da Universidade de Lisboa. A autora Alice Rocha da Silva agradece à Fundação de Apoio à Pesquisa do Distrito Federal (FAP-DF) pelo financiamento concedido para a realização de estágio pós-doutoral (Edital 05/2018) na Université de Paris, quadro de desenvolvimento da presente pesquisa.

Doutora em Direito Público/Direito Comunitário pela Universidad Alcalá de Henares - Madrid. Mestre em Direito pela UAH, Madrid Master en Instituciones y Políticas de la UE - UCJC/Madrid. Coordenadora do Centro de Excelência Europeu Jean Monnet UFMG. Professora da Faculdade de Direito da Universidade Federal de Minas Gerais (UFMG). Professora da ESDHC. Coordenadora e professora do PPGD da Universidade de Itaúna. Coordenadora da Rede de Pesquisa "Integração, Estado e Governança”. Belo Horizonte - MG - BR. E-mail: <jmatadiz@yahoo.com.br>. https://orcid.org/00000001-8709-0616

" Doutora em Direito Internacional pela Universidade de São Paulo. Professora da Universidade Europeia de Lisboa. Advogada no Brasil e em Portugal. Lisboa, Portugal. E-mail: <ebeth.accioly@gmail.com>. https://orcid.org/0000-0002-1877-5109

${ }^{* * *}$ Doutora em Direito Internacional Economico pela Universite Aix- -Marseille III. Mestre em Direito das Relações Internacionais pelo UniCEUB. Graduada em Direito pelo UniCEUB e em Ciência Política e Relações Internacionais pela Universidade de Brasília. Professora do Programa de Mestrado e Doutorado em Direito do Centro Universitário de Brasília (UniCEUB). Email: <rochaalice@yahoo.com.br>. https://orcid.org/0000-0002-0222-2737 
propagação rápida de uma pandemia, tendo a solidariedade como fundamento da própria existência do espaço europeu integrado.

Metodologia: $\mathrm{O}$ trabalho foi estabelecido a partir da análise do arcabouço institucional e legal da União Europeia, desde o pedido de auxílio feito pela Itália em fevereiro de 2020, delimitando-se, a partir, deste recorte temporal, as medidas utilizadas pela União para mitigar os efeitos da crise. A partir de uma metodologia histórica e dedutiva o conteúdo das premissas foi especificado, a partir de um binômio correto/incorreto, válido/inválido, real/fictício, não havendo níveis definitivos de conclusão.

Resultados: Com uma linha do tempo específica, concluiu-se que apesar de contar com instrumentos específicos, tais não foram suficientes para evitar a rápida disseminação e contágio gerado pelo COVID-19.

Contribuições: As duas principais contribuições desta pesquisa foram de demonstrar a necessidade de incremento aos mecanismos de proteção civil europeu, evitando que as decisões sejam tomadas com "atraso" e sem apresentar soluções efetivas, assim como reforçar o dever de solidariedade como parâmetro para ações concretas que venham a especificar em que medida cada Estado pode cooperar com os demais, sempre sob o manto da União Europeia. Vale mencionar que a escolha pela análise da União Europeia se deve ao fato desta representar um referencial de integração cooperativa e dialógica, num espaço de auxílio e cooperação mútuos que poderia servir como modelo para outras regiões.

Palavras-chaves: União Europeia. Solidariedade. Sistema de proteção civil. COVID-19.

\section{ABSTRACT}

Objective: This article seeks to establish how the procedures and standards established by the European Union were determined in the face of the crisisgenerated by the rapid spread of a pandemic, with solidarity can be invoked as the foundation of the very existence of the integrated European space.

Methodology: The work was established from the analysis of the institutional and legal framework of the European Union, since the request for assistance made by Italy in February 2020, delimiting, from this time frame, the measures used by the Union to mitigate the effects of the crisis. Based on a historical and deductive methodology, the content of the premises was specified, based on a correct / incorrect, valid / invalid, real / fictitious binomial, with no definitive levels of conclusion.

Results: With a specific timeline, it was concluded that despite having specific instruments, these were not sufficient to prevent the rapid dissemination and contagion generated by COVID-19.

Contributions: The two main contributions of this research were to demonstrate the need to increase the European civil protection mechanisms, avoiding that decisions are taken "late" and without presenting effective solutions, as well as reinforcing the duty of solidarity as a parameter for concrete actions that may come to specify to what extent each State can cooperate with the others, always under the mantle of the European Union. It is worth mentioning that the choice for the analysis of the European Union is due to the fact that it represents a benchmark for cooperative and dialogical integration, in a space of mutual aid and cooperation that could serve as a model for other regions.

Keywords: European Union. Solidarity. Civil protection system. COVID-19. 


\section{RESUMEN}

Objetivo: Este artículo busca establecer cómo se determinaron los procedimientos y estándares establecidos por la Unión Europea ante la crisis generada por la rápida propagación de una pandemia, con la solidaridad como fundamento de la existencia misma del espacio europeo integrado.

Metodología: El trabajo se estableció a partir del análisis del marco institucional y legal de la Unión Europea, desde la solicitud de asistencia realizada por Italia en febrero de 2020, delimitando, a partir de ese marco temporal, las medidas utilizadas por la Unión para mitigar los efectos de la crisis. Con base en una metodología histórica y deductiva, se há puesto de relieve el contenido, bajo el supuesto del binomio / incorrecto, válido / inválido, real / ficticio, sin niveles definitivos de conclusión.

Resultados: Con un recorte específico, se concluyó que a pesar de contar con instrumentos específicos, estos no fueron suficientes para prevenir la rápida propagación y contagio que genera el COVID-19.

Contribuiciones: Los dos principales aportes de esta investigación han demonstrado la necesidad de incrementar los mecanismos de protección civil europeos, evitando que las decisiones se tomen "de forma reactiva" y sin presentar soluciones efectivas, así como reforzar el deber de solidaridad como parámetro para acciones concretas además de precisar en qué medida cada Estado puede cooperar con los demás, siempre bajo el manto de la Unión Europea. Cabe mencionar que la elección para el análisis de la Unión Europea se debe a que representa un referente de integración cooperativa y dialógica, en un espacio de ayuda mutua y cooperación que podría servir de modelo para otras regiones.

Palabras clave: Unión Europea. Solidaridad. Sistema de protección civil. COVID-19.

\section{INTRODUÇÃO}

A reação da União Europeia (UE) à propagação do novo coronavírus, COVID-19, assim denominado pela Organização Mundial da Saúde (OMS), representa um desafio inconteste ao processo de integração que só será bem-sucedido com uma ação solidária. Diante do contexto atual e da emergência de uma grave crise sanitária que resultou na decretação de estado de pandemia global pela OMS, faz-se imprescindível analisar a reação dos Estados aos efeitos e às consequências da propagação de um vírus que desconhece fronteiras territoriais ou legais. Tal análise demanda por parte dos pesquisadores um estudo cuidadoso, ainda que parcialmente validado, tendo em vista a natureza imprevisível da situação e a necessidade de uma resposta inovadora.

A União Europeia possui uma estrutura diferenciada dos demais processos de integração, com instituições consolidadas e experiência no enfrentamento de crises. Todavia, nenhum país ou sistema estava preparado para a crise do COVID-19, e, rapidamente, Itália e Espanha se transformaram no epicentro de propagação do vírus (dados de março de 2020), representando para o bloco um "teste de fogo", especialmente para a manutenção do sistema institucional e jurídico comum.

Nesse sentido, o presente artigo pretende examinar em que medida a atuação da União Europeia realmente demonstrou (ou não) ser compatível com os valores e os objetivos fixados desde o instrumento fundacional do processo de integração europeu, em 1950, pelo então Tratado de Roma. A trajetória ímpar desse processo de integração 
resultou na criação de um sistema institucional e jurídico próprio, com características, natureza e regulação singulares, diferenciando-se dos esquemas tradicionais de negociação e cooperação adotados pelo Direito Internacional e, também, das próprias organizações internacionais clássicas.

O enfoque deste trabalho será analisar o desenvolvimento da atuação da União Europeia, a partir de medidas adotadas para a contenção da crise sanitária, com destaque para a aplicação do dever de solidariedade dentro dos limites das competências fixadas. Serão verificadas as principais medidas tomadas pela UE, com fundamento em um dado recorte temporal ( 26 de fevereiro a 6 de abril), uma vez que as variáveis e os parâmetros de resposta mudam permanentemente, devido à própria imprevisibilidade gerada pela propagação do COVID-19. Deve-se salientar que as estimativas feitas diariamente, apesar de todos os recursos científicos e tecnológicos, demandam uma atenção maior para que não haja distorções quali-quantitativas que possam ser objeto de posterior refutação, especialmente ancoradas em discursos e análises metajurídicas e, ainda mais preocupante, sem o rigor que se deve ter no marco de uma pesquisa considerada científica.

A eleição do recorte temporal anteriormente mencionado, deveu-se, em grande medida, a três aspectos primordiais: i) a "volatilidade" das medidas em função do agravamento da crise no espaço europeu; ii) a constatação de ações unilaterais por parte de alguns Estados sem que houvesse um diálogo consensual entre os Estados e a própria União; e iii) a dificuldade inicial gerada pela sinergia do processo decisório nacional/regional, a partir da resposta (considerada "tardia") dada pela UE, em especial no caso da Itália, relegando a segundo plano o dever de cooperação fixado pelo artigo 222, numeral 3.1, do Tratado Funcionamento da União Europeia (TFUE). Este artigo dispõe sobre a chamada "cláusula de solidariedade" que determina a obrigação de auxílio mútuo entre os Estados-membros e a própria União, em caso de catástrofe natural ou humana e, ainda, quando houver ataque terrorista. Conforme será analisado posteriormente, há regramento que estabelece o funcionamento de tal cláusula, bem como fixa os parâmetros para que os Estados possam dela se utilizar.

A metodologia de trabalho centra-se nos aspectos principais estabelecidos para uma pesquisa interdisciplinar que envolve temas de direito da integração e seu tratamento pela organização supranacional em esquemas de compartilhamento de competências (Estado e organização), devido especialmente ao caráter específico e singular que deve estar presente em toda a análise de um sistema jurídico cujo foco se baseia em conferir um dever de solidariedade e a criação de mecanismos específicos para a gestão de crises.

Nesse sentido, devem-se utilizar métodos que permitam analisar como se poderia adotar um sistema realmente eficiente para que, diante de um cenário de incertezas e imprevisibilidade, fossem criadas medidas efetivas para dirimir o tempo de resposta necessário para a mitigação dos efeitos da crise. O método dedutivo permitiu estabelecer o recorte institucional marcadamente voltado para a União Europeia e seu sistema jurídico, mediante a análise de um caso concreto baseado em uma organização com 27 membros, de acordo com um temporal específico do dia 26 de fevereiro - data em que a Itália invoca os instrumentos de solidariedade - até o dia 6 de abril - momento em que se consegue estabelecer, ainda que de forma preliminar, as principais medidas tomadas pela União Europeia, tendo como foco o caso do COVID-19, para responder à invocação da cláusula de solidariedade pela Itália. Na presente pesquisa, como os resultados ainda são parciais, a conclusão se dará, exclusivamente, com base nos dados coletados e disponibilizados pelos órgãos oficiais da UE. 


\section{O PROCESSO DECISÓRIO SOBRE O ENFRENTAMENTO DO COVID-19 DENTRO DAS COMPETÊNCIAS EUROPEIAS}

A União Europeia, desde sua origem, em 1950, com o Tratado do Carvão e do Aço (TCECA) e o Tratado Europeu de Energia Atômica (EURATOM), foi, paulatinamente, construindo um sistema jurídico e institucional autônomo, ainda que em modo de compartilhamento com os Estados-membros, o que lhe possibilitou, ao longo do tempo, dimensionar e concentrar as competências que lhe foram atribuídas pelos respectivos membros, culminando, em 2009, a partir do Tratado de Lisboa, com a adoção de um rol de competências específico.

Em breve contextualização histórica, o TCECA estabeleceu um modelo de colaboração que influiria decisivamente no processo integrativo subsequente. Concomitante ao Tratado da Comunidade Europeia do Carvão e do Aço, seguiram-se o Tratado da Comunidade Econômica Europeia (CEE) e o Tratado da Comunidade Europeia de Energia Atômica, ambos celebrados em 1957 (MAGNOLI, 1995). Assim, três comunidades se estruturaram no continente europeu, as quais instituíram um Conselho e uma Comissão únicos, a congregar todas elas. Por meio do Tratado de Bruxelas, firmado em 1965, formou-se aparato orgânico composto por quatro instituições seminais à fase ulterior de integração: o Parlamento, a Corte de Justiça, o Conselho e a Comissão únicos, que compunham o então nascente Mercado Comum Europeu.

Todavia, o grande passo para a formação da vindoura União Europeia foi dado com a assinatura, em 1986, do Ato Único Europeu, visando ao aprofundamento da integração econômica e lançando as bases para maior integração econômica e política, que culminou no advento do Tratado de Mastricht (1992) e na consolidação definitiva da União Europeia. Desta feita, o Direito Comunitário inaugura novas formas de produção e aplicação normativas, corporificando uma inflexão em face do Direito Internacional clássico. Surge, portanto, um ordenamento jurídico autônomo (MATA DIZ; JAEGER JUNIOR, 2015), que se integra aos ordenamentos jurídicos internos segundo determinados princípios, cuja força cogente é garantida por um Poder Judiciário próprio, representado pelo Tribunal de Justiça da União Europeia (TJUE).

Contudo, o exercício dos poderes conferidos a essa organização supranacional que não pertence a nenhum Estado (muito menos, deve se subordinar, especificamente, a um comando estatal único) mas, por meio da supranacionalidade, a eles se dirigem mediante suas respectivas decisões (legislativa, executiva e judicial), nos interessa, para a compreensão da crise e da capacidade de resposta e dever de solidariedade da UE, estabelecer, ainda que, de modo panorâmico, as competências a ela atribuídas, em especial em matéria de políticas públicas de saúde.

\subsection{PRINCÍPIOS DE REGÊNCIA DA COMPETÊNCIA}

O reconhecimento do "agire" da União, mediante o princípio da atribuição, encontra-se claramente delimitado nos artigos $4^{\circ}$. e $5^{\circ}$. do Tratado da União em que se dispõe que a UE somente poderá atuar naquelas matérias cujo poder decisório houver sido transferido pelos próprios Estados, e.g., a União - enquanto organização composta por Estados - depende, portanto, da aprovação destes para que, em princípio, possa realizar tal ou qual medida, programa, ação, projeto, etc. Esse princípio ostenta certa proximidade com esquemas federalistas (em especial, o alemão), contudo apresenta características específicas, pois, por um lado, essa determinação obedece a critérios teleológicos e/ou funcionais e não 
materiais, e, por outro, o reconhecimento da competência implícita para a preservação dos valores e dos objetivos da União (dispostos nos artigos $2^{\circ}$. e $3^{\circ}$. do Tratado de Lisboa) da União, conforme será posteriormente analisado.

Além disso, uma vez atribuída a competência à União, para seu respectivo exercício, adotam-se, como pilares essenciais, os princípios da subsidiariedade e da proporcionalidade, em especial quando se trata das competências compartilhadas e das competências inominadas (apoio e/ou complementar). O primeiro - subsidiariedade - determina que a União somente poderá intervir na medida em que os objetivos da atuação que visa a realizar não possam ser suficientemente alcançados pelos Estados-Membros, devido à dimensão ou aos efeitos da ação que se queira executar (DEL POZO; MATA DIZ, 2013). O princípio, muito debatido, significa uma garantia para a democracia, uma limitação da administração comunitária, bem como dos recursos da União e encontra-se devidamente regulado no Protocolo n. 2 anexo ao Tratado de Lisboa (MATA DIZ; CARNEIRO, 2017).

O segundo - proporcionalidade - imbrica que o conteúdo e a forma da ação que a União pretenda realizar não pode, em caso algum, exceder aquilo que for imprescindível para alcançar a realização dos objetivos definidos nos Tratados. Diante de uma escolha entre várias medidas adequadas que podem ser adotadas tanto pela União como pelos Estados, deve-se recorrer à menos onerosa, e os inconvenientes causados não devem ser desproporcionais aos objetivos perseguidos. Vale ressaltar que o TJUE aplica o princípio da proporcionalidade para o referido sistema de distribuição das competências, notadamente, aquelas que são compartilhadas entre as instituições comunitárias e os Estados-membros, servindo, portanto, como parâmetro e como medida de controle da própria União (MATA DIZ; CARNEIRO, 2017).

\subsection{A DEFINIÇÃO DA COMPETÊNCIA RELACIONADA À POLÍTICA DE SAÚDE NO CONTEXTO EUROPEU}

O TFUE reconhece três categorias de competências: i) explícitas (exclusivas; compartilhadas e chamadas competências inominadas, de apoio e/ou complementar); ii) competências implícitas e iii) competências subsidiárias, segundo disposto no Tratado de Lisboa. As competências explícitas encontram-se sistematizadas nos artigos $3^{\circ}$ ao $6^{\circ}$ do Tratado de Funcionamento da União, enquanto a competência implícita resulta da intepretação, majoritariamente jurisprudencial, relativa à concretização dos valores e dos objetivos da União. Já a competência subsidiária está fixada pelo artigo 352 do TFUE.

Essa classificação, adotada a partir de 2009, facilitou a compreensão dos limites entre atuação da União e dos Estados-membros, sem que, contudo, possa ser considerada a solução definitiva para todos os problemas. Tal se dá porque ainda subsiste a possibilidade de utilizar-se da competência dita implícita para o cumprimento dos valores e dos objetivos da União. Explique-se: ainda que não haja definição prévia se uma competência compartilhada e/ou de apoio deve ser exercida pela União, o fato de comprovar-se a aplicação da subsidiariedade e da proporcionalidade fornece à UE larga vantagem de atuação quando comparada com os Estados-membros.

A política de saúde, por exemplo, encontra-se determinada como uma competência de apoio ou complementar estando sua regulação sob a égide de cada Estado, contudo, para a preservação dos elementos vinculados aos valores e aos objetivos, entre eles, o funcionamento do mercado comum - este sim de competência exclusiva da UE - poderia ser utilizada a cláusula da competência implícita para fixar instrumentos conjuntos (de 
natureza normativa, técnica e/ou operacional) a serem observados por todos os Estadosmembros.

A competência implícita pode ser considerada como elemento fundamental para a compreensão da atribuição de funções à União, pois "[...] Esta competência implícita deriva, na realidade, da existência de uma competência interna, isto é, da adaptação e implementação de uma ação no âmbito de uma política comunitária." ${ }^{2}$ (BOUTAYEB, 2018, p. 218).

Ainda, o reconhecimento e o exercício das competências implícitas ancoradas nos objetivos e nos valores da União e, ainda, na concretização da competência exclusiva do mercado comum com as chamadas quatro liberdades fundamentais (circulação de pessoas, bens, capitais e serviços) foram paulatinamente sendo desenvolvidos pela jurisprudência do Tribunal de Justiça da União Europeia ${ }^{3}$, reforçando o caráter amplo e plurissignificativo que conferiu à organização europeia o exercício de determinados poderes que não se encontravam plenamente fixados nos Tratados fundacionais, consoante sublinha Del Pozo e Mata Diz (2013, p. 25):

Por sua vez, o Tribunal de Justiça da União Europeia também tem apoiado a tese dos poderes implícitos em seu trabalho de construção jurisprudencial da ordem jurídica comunitária, reconhecendo a existência de competências implícitas em várias situações. Estes incluem a competência para celebrar acordos internacionais em questões em que os Tratados não contemplam essa faculdade, mas sim atribuem à Comunidade uma competência interna e a de criar organismos especializados em estruturas setoriais. Da mesma forma, é possível considerar a adoção de atos comunitários não tipificados pelos Tratados e incentivados por força jurídica variada, como resultado do exercício de competências implícitas, que a doutrina catalogou na categoria de atos atípicos, ou seja, resoluções, programas, declarações, etc. ${ }^{4}$

Além disso, o artigo 168 do TFUE estabelece, nomeadamente, que deve ser assegurado um elevado nível de proteção da saúde humana na definição e na execução de todas as políticas e ações da União. Este artigo estabelece, por um lado, que a ação da União deve complementar as políticas nacionais e abranger a vigilância, o alerta e o combate contra as ameaças graves para a saúde com dimensão transfronteiriça. Por outro, os Estados-Membros devem coordenar entre si, em conjunto com a Comissão, as respectivas políticas e os programas nos domínios abrangidos pela União em matéria de saúde pública.

Por fim, deve-se mencionar a disposição contida no artigo 352 que reforça a possibilidade do exercício implícito de competência por parte da União (sempre com base nos princípios da subsidiariedade e da proporcionalidade), sufragando o posicionamento a partir da real atuação para garantir o mercado comum e lograr os objetivos da União, ainda que sem poderes expressos consagrados ou previstos pelos Tratados. Abre-se, aqui, ampla

\footnotetext{
${ }^{2}$ No original: "Cette compétence implicite decoule, en realité, de l'existence d'une competénce interne, c'est-à-dire de l'adaptation et la mise en ouvre d'une action dans le cadre d'une politique communautaire."

${ }^{3}$ Vide a decisão paradigmática AETR.

${ }^{4}$ No original: Por su parte, el Tribunal de Justicia de la Unión Europea se ha venido apoyando también en la tesis de los poderes implícitos en su labor de construcción jurisprudencial del ordenamiento jurídico comunitario, reconociendo la existencia de competencias implícitas en diversas situaciones. Entre ellas destacan la competencia para concluir acuerdos internacionales en materias donde los Tratados no contemplan esta facultad pero sí atribuye a la Comunidad una competencia interna11, y la de creación de órganos especializados en marcos sectoriales. Igualmente, es posible considerar fruto del ejercicio de competencias implícitas la adopción de actos comunitarios no tipificados por los Tratados y animados de variada fuerza jurídica, que la doctrina ha catalogado dentro de la categoría de actos atípicos, es decir, resoluciones, programas, declaraciones, etc.
} 
margem interpretativa para que a União possa, além das competências já estabelecidas, exercer poderes e/ou ações necessários para tal missão ${ }^{5}$.

Portanto, a conjugação da competência implícita com os artigos 6º 168 e 352 do TFUE abriria a possibilidade de uma atuação mais firme por parte da União, avocando para si as medidas a fim de evitar a propagação do vírus, com ações de contenção a serem observadas conjuntamente por todos os Estados-membros, evitando, assim, medidas unilaterais que venham a afetar a unidade normativa já alcançada pela UE, por exemplo, em matéria de livre circulação - pilar fundamental do mercado comum.

\section{O ENFRENTAMENTO DO COVID-19 A PARTIR DOS INSTRUMENTOS PREESTABELECIDOS PELO SISTEMA EUROPEU}

Não é a primeira vez que o sistema europeu enfrenta crises não somente sanitárias e de saúde pública, mas também causadas por catástrofes ambientais. A partir dessa vasta experiência, a UE possui alguns mecanismos que poderiam ser utilizados para o enfrentamento do COVID-19. Dentre eles, temos o Mecanismo de Proteção Civil, o Centro Europeu de Prevenção e Controle de Doenças e o Sistema de Alerta Rápido e Resposta (SARR).

Tais instrumentos servem como suporte operacional, técnico e de gestão às instituições europeias no âmbito do processo decisório e do exercício das competências, como já analisado anteriormente. Também são imprescindíveis para a compreensão do procedimento de invocação da cláusula de solidariedade, por isso, serão analisados de forma mais detalhada.

\subsection{O MECANISMO DE PROTEÇÃO CIVIL COMO CATALIZADOR DE MEDIDAS COMUNS EM CASO DE CATÁSTROFES}

A União Europeia criou, em 2001, um mecanismo institucional denominado Mecanismo de Proteção Civil da União Europeia (EUCPM - sigla em inglês) destinado a coordenar ações conjuntas dos Estados-membros ${ }^{6}$ em caso de desastres, catástrofes ou acidentais naturais e/ou causados pelo homem. Nesse sentido, o mecanismo busca dar uma resposta rápida, eficiente e conjunta ante tais circunstâncias que, apesar de terem, em geral, um espectro nacional, podem alcançar outros Estados membros ou não da União como é o caso do COVID-19.

Esse Mecanismo permite à União adotar medidas necessárias para, de forma coordenada, auxiliar no combate aos desastres e às emergências nacionais e internacionais, atuando de forma a operacionalizar os esforços sob um marco comum de ação, conforme dispõe o artigo 196 do TFUE e a Decisão n. 1313/2013/EU (UNIÃO EUROPÉIA, 2013). Sob a perspectiva organizacional e normativa, tal Mecanismo compreende:

Centro Europeu de Coordenação de Resposta a Emergências (CECRE): órgão responsável pela prestação de auxílio imediato aos Estados, aos grupos ou às pessoas afetadas, representa o teatro de operações estratégico, assegurando um rápido deslocamento de

\footnotetext{
${ }^{5}$ Vale ressaltar que há uma diferença substancial entre a competência implícita e a competência subsidiária, uma vez que nem os requisitos necessários para recorrer a ambas, nem os procedimentos para decidir pela respectiva aplicação, em cada caso, nem as respectivas intensidades e extensões são comparáveis. Enquanto a competência subsidiária, considerada meramente acessória, derivada diretamente das competências previamente estabelecidas de modo a reforçá-las, a competência implícita tem um caráter evidentemente inovador e, sem dúvida, uma intepretação ainda mais aberta.

${ }^{6}$ Participam também Islândia Macedônia, Montenegro, Noruega, Sérvia e Turquia.
}

84 - R. Opin. Jur., Fortaleza, ano 18, n. 29, p.77-97, set./dez. 2020 
recursos, uma vez que se conecta diretamente com as instituições nacionais de proteção civil. Conforme ressalta a própria Comissão Europeia,

Desde 2001, o Mecanismo de Proteção Civil da União Europeia (EUCPM) foi ativado mais de 300 vezes em resposta a países que solicitaram assistência de emergência europeia. A UCPM ajudou a população em alguns dos desastres mais devastadores, tanto na Europa quanto no mundo. Somente durante a intensa temporada de incêndios em 2017, o Mecanismo foi ativado 17 vezes para ajudar os países europeus a combater o incêndio (COMISÍON EUROPEA, 2018, online). ${ }^{7}$

Capacidade de resposta e emergência: ferramenta operacional que tem por objetivo criar um fundo comum de voluntários, equipamentos e pessoal especializado, buscando garantir um planejamento e uma atuação imediata, coerente e eficaz disponibilizado por todos os Estados participantes, mediante o intercâmbio de experiências, material e recursos humanos e de infraestrutura.

Gestão de desastres: além dos instrumentos citados anteriormente, há uma proposta da Comissão para fortalecer ainda mais, de forma mais célere, a resposta coletiva especialmente no caso dos chamados desastres e/ou catástrofes simultâneas (ou crise coletiva, como é o caso do COVID-19). Citando especificamente as catástrofes "naturais" (queimadas intensas que provocaram incêndios em 12 Estados da UE ao longo dos três últimos anos), a Comissão criou o programa "rescUE" com o objetivo de, justamente, reforçar o papel da União diante de um cenário de crise de natureza ambiental, epidemiológica, energética, etc., acelerando o tempo de resposta e a gestão eficiente dos recursos. Esse programa teve como principal elemento a proposta do Conselho Europeu para prestar assistência aos Estados nos casos em que as capacidades nacionais existentes fossem consideradas insuficientes (UNIÃO EUROPÉIA, 2019).

Nessa proposta, que está sendo analisada pelas instituições comunitárias, há dois pontos importantes: i) a criação de um centro de resposta próprio da União, independente dos Estados, com equipamentos que estarão sob a custódia da própria organização (aeronaves, aparelhos hidráulicos de alta pressão para o combate ao fogo, hospitais de campanha e material hospitalar) cujo financiamento e aquisição se dará pela União; ii) o reforço das capacidades nacionais ao estabelecer uma linha de financiamento para os Estados destinada à adaptação, à preparação, ao transporte e à operação dos recursos já existentes nos Estados-membros, que seriam compartilhados por todos os participantes, em caso de emergências, sob o comando do EUCPM, devendo ser imediatamente disponibilizados para operação em caso de desastres.

Sobre a utilização anterior do EUCPM, há relatório elaborado pela Comissão, mediante estudo de três casos externos (as inundações na Bosnia-Herzegovina em 2014, o desenvolvimento do vírus ebola na África Ocidental entre março de 2014 e janeiro de 2016 e o terremoto do Nepal, em 25 de abril de 2015). A auditoria feita nesses três casos apresenta resultados interessantes para a compreensão do tempo de resposta e da necessidade de aprimoramento do Mecanismo, em especial do sistema de alerta rápido (EUROPA, 2016). É interessante notar que, na proposta feita em 2017, há uma pequena nota enfatizando a necessidade de aprimorar o Mecanismo, simplificando o procedimento

\footnotetext{
${ }^{7}$ No original: "Desde 2001, el Mecanismo de Protección Civil de la Unión Europea (EUCPM) se ha activado más de 300 veces en respuesta a los países que solicitaron asistencia europea frente a emergencias. El UCPM ha asistido a la población en algunos de los desastres más devastadores, tanto en Europa como en todo el mundo. Solo durante la intensa temporada de incendios forestales de 2017, el Mecanismo se activó en 17 ocasiones para ayudar a los países europeos a combatir el fuego.”
} 
administrativo (less burocracy) para reduzir o tempo de resposta que, em caso de catástrofes (especialmente de natureza altamente expansiva e com alto índice de propagação como é o COVID-19), pode ser crucial na salvaguarda da vida.

Também digno de nota foi a menção específica feita ao rescUE pela Presidência do Conselho da União Europeia em seu programa semestral adotado pela Croácia, Estado que assumiu a direção da instituição (PROGRAMME OF CROATIAN PRESIDENCY OF THE COUNCIL OF THE EUROPEANUNION, 2020, p. 26):

\begin{abstract}
A ênfase será colocada na implementação adicional de todos os componentes do Mecanismo de Proteção Civil da UE (rescEU). Refere-se principalmente às capacidades de resposta a ameaças químicas, biológicas, radiológicas e nucleares, estabelecimento de primeiros socorros, gerenciamento de capacidades de resgate temporárias da UE para proteção e sua transição para capacidades permanentes. A Presidência croata trabalhará para o estabelecimento da Rede de Conhecimento de Proteção Civil da UE e para um maior reconhecimento do papel da UE em salvar a vida de seus cidadãos. ${ }^{8}$
\end{abstract}

Feitas as breves considerações sobre o EUCPM e a sua modelagem institucional e normativa, para o presente artigo, interessa mencionar que a Itália - primeiro Estado europeu a apresentar alto índice de contágio pelo COVID-19 - acionou o Mecanismo em 26 de fevereiro de 2020, solicitando à União Europeia o envio de material hospitalar e sanitário, especialmente máscaras e outros equipamentos de proteção para o atendimento dos pacientes pelos centros hospitalares.

Contudo, não há dados oficiais disponíveis que permitam verificar o momento exato de atendimento à solicitação feita àquela data. Em uma sucinta linha do tempo, pode-se verificar que o pedido foi feito em 26 de fevereiro de 2020, tendo o Comissário para gestão da crise Janis Lenarcic, respondido em 27 de fevereiro que a União estaria estudando as medidas, inclusive financeiras, para apoiar o estado italiano. Em 6 de março, o Comissário, após a Reunião do Conselho Extraordinário da Saúde, assinalou que a situação "exige medidas específicas, e outros países da UE devem examinar essas medidas, observar a experiência italiana e se preparar: porque é mais provável que em breve haja situações semelhantes na Europa [...]." (LENARCIC, 2020, online).

Nessa mesma ocasião, o referido Comissário Lenarcic havia estabelecido uma agenda de gestão comum para o fornecimento de materiais médicos e equipamentos de proteção, aquisição que seria feita por meio do procedimento de contratação pública europeia, tendo em vista a necessidade de analisar os pedidos específicos que já haviam sido encaminhados por 20 Estados-Membros.

Conforme informação extraída da página web da União Europeia, foram feitas quatro chamadas (modalidade concurso na legislação europeia, similar ao nosso pregão):

a) aquisição de equipamentos e suprimentos médicos, especialmente luvas e aventais cirúrgicos, em 28 de fevereiro;

b) aquisição de equipamentos de proteção individual, em 4 de março;

\footnotetext{
${ }^{8}$ No original: The emphasis will be placed on further implementation of all the components of the EU Civil Protection Mechanism (rescEU). This primarily refers to the capacities for response to chemical, biological, radiological and nuclear threats, establishment of -rst aid, management of temporary rescEU capacities for -re protection, and their transition to permanent capacities. The Croatian Presidency will work towards the establishment of the EU Civil Protection Knowledge Network and a higher recognisability of the EU's role in saving the lives of its citizens
}

86 - R. Opin. Jur., Fortaleza, ano 18, n. 29, p.77-97, set./dez. 2020 
c) proteção ocular e respiratória, bem como ventiladores médicos e equipamento respiratório, em 17 de março e;

d) suprimentos laboratoriais e kits de teste em 19 de março, com empresas participantes originárias de 25 Estados-membros (EUROPEAN COMMISSION, 2020). Contudo, até o dia 30 de março de 2020, não havia, na página web oficial da União, informações precisas sobre a efetiva aquisição de tais bens.

No dia 31 de março, foram estabelecidas Orientações da Comissão Europeia sobre contratos públicos na situação de emergência relacionada com a crise COVID-19 (2020/C 108 I/01) (UNIÃO EUROPÉIA, 2020a) que explicitam as situações excepcionais relativas ao marco geral de contratação pública europeia (Diretiva 2014/24/UE do Parlamento Europeu e do Conselho, de 26 de fevereiro de 2014), tais como flexibilidade de prazos, meios de contratação sem publicação, regras em caráter emergencial. Dado o escopo do presente artigo e a natureza extremamente complexa do processo de contratação público europeu, não será realizado um estudo exaustivo de tais orientações, cabendo, contudo, citá-los como uma das medidas tomadas pelas instituições europeias.

\subsection{CENTRO EUROPEU DE PREVENÇÃO E CONTROLE DE DOENÇAS}

No marco da gestão da crise, deve-se mencionar também a atuação do Centro Europeu de Prevenção e Controle de Doenças (ECDC - sigla em inglês), agência que se destina, justamente, a fortalecer as ações da Europa no combate a doenças infecciosas, abarcando uma série de funções relativas à vigilância e à inteligência no combate às crises epidemiológicas, entre outras atividades.

Criado pelo Regulamento 851/2004/CE do Parlamento Europeu e do Conselho, de 21 de abril de 2004 (UNIÃO EUROPÉIA, 2004, online), o EDCD tem por objetivo, conforme disposto no artigo 3o do Regulamento, "identificar, avaliar e comunicar as ameaças atuais e emergentes para a saúde humana derivadas de doenças transmissíveis.” Além disso, o Centro pode atuar de forma autônoma e por iniciativa própria, "no caso de outros surtos de doenças de origem desconhecida que possam propagar-se quer a partir do exterior da Comunidade quer dentro do seu próprio território." (UNIÃO EUROPÉIA, 2004, online, grifo nosso).

Essa situação se encontra plenamente enquadrada no atual contexto da crise causada pelo COVID-19. Contudo, nota-se, também, uma demora institucional em acionar os instrumentos previstos no próprio Regulamento, em especial o Sistema de Alerta Rápido e Resposta (SARR), que será posteriormente comentado.

Especificamente no que se refere ao COVID-19, o EDCD tem propiciado uma série de informações, protocolos e medidas que devem ser observadas pelos Estados, além de significar uma fonte referencial sobre os índices de propagação, sistematização dos dados nacionais, regionais e internacionais, bem como facilitar a interface entre os órgãos nacionais voltados para o combate epidemiológico e as instituições e os órgãos da própria União Europeia.

Conforme assinalam Widmalm, Parker e Persson (2019, p. 14-15), a atuação do EDCD,

[...] Está possibilitando uma gestão conjunta de crises e incentivando uma maior cooperação para a proteção civil. Isso é feito através da criação de instituições comuns e da tentativa de melhorar as capacidades da UE. Instituições comuns, no entanto, podem ser necessárias, mas não suficientes, para facilitar a cooperação. Ao criar uma estrutura institucional 
nessa área, a União e seus Estados-membros estão enfrentando uma série de importantes desafios relacionados à confiança, cultura e legitimidade que são parte integrante da qualidade da ação coordenada e da resposta a crises. Se os novos arranjos pretendem melhorar a gestão de futuros desastres e crises, é fundamental que esses desafios sejam superados. ${ }^{9}$

Desde a decretação da pandemia em 14 de março de 2020, o EDCD tem apresentado dados atualizados sobre cada um dos Estados, coletando-os pelo intercâmbio de informações com as respectivas autoridades nacionais, contrastando-os também com os dados de plataformas internacionais. A título de exemplo, no dia 6 de abril de 2020, marco temporal de recorte do presente artigo, a página web oficial do EDCD apresentava os seguintes números (EUROPEAN CENTRE FOR DISEASE PREVENTION AND CONTROL, 2020): 582.554 casos de contágio e 47.741 mortes, sendo os Estados mais afetados, respectivamente, Espanha (130.759), Itália (128.948), Alemanha (95.391), France (70.478), Reino Unido (47.806) - número de contágios - e Itália (15.889), Espanha (12.418), França (8.078), Reino Unido (4.934), Holanda (1.651) - números relativos às mortes reportadas em virtude do COVID- 19.

\subsection{SISTEMA DE ALERTA RÁPIDO E RESPOSTA (SARR)}

Deve-se mencionar, ainda, que se processa no marco do EDCD, em conjunto com a Comissão Europeia e as respectivas autoridades de saúde pública nacionais, o Sistema de Alerta Rápido e Resposta (SARR), uma plataforma digital que contém todas as informações e as medidas para controlar sérias ameaças transfronteiriças à saúde, incluindo doenças transmissíveis. Criado pela Decisão 2119/98/CE de vigilância epidemiológica e de controle das doenças transmissíveis, constitui, portanto, um fluxo de comunicações constante entre a Comissão e as autoridades de saúde pública em cada Estado-Membro, por meio dos meios adequados especificados na Decisão 2000/57/CE da Comissão, de 22 de dezembro de 1999, relativa ao sistema de alerta rápido e de resposta, para a prevenção e o controle das doenças transmissíveis concretizando o disposto na Decisão 2119/98/CE do Parlamento Europeu e do Conselho.

O procedimento para adoção do SARR estabeleceu-se pela Decisão de Execução 2017/253, a qual especifica as medidas de notificação de alerta no âmbito europeu, especialmente em relação a graves ameaças transfronteiriças à saúde, para o intercâmbio de informações, consulta e coordenação de respostas a tais ameaças. Segundo sublinhado pela Comissão Europeia, ao referir-se à importância do SAAR, "ao longo dos anos, desempenhou um papel importante no apoio à crise de saúde relacionada à síndrome respiratória aguda grave (SARS), doença pelo vírus Ebola, influenza aviária em humanos e outras doenças transmissíveis.”

Contudo, uma vez mais, não há dados suficientes para afirmar que o EDCD vinha atuando desde dezembro 2019 e/ou janeiro de 2020 para notificar, alertar e preparar, em caráter prévio, os Estados-membros em relação à propagação do Covid-2019. A primeira consulta feita pelas autoras do presente artigo, em 11 de março de 2020, não apresentava

\footnotetext{
${ }^{9}$ No original: [...] It is enabling more joint crisis management, and encouraging greater cooperation for civil protection. It is doing by building common institutions and trying enhance capacities at the EU level. Common institutions, however, may be necessary but not sufficient for facilitating cooperation. As they build up an institutional framework in this area, the Union and its member states are confronting a number of importante software challenges relating to trust, culture and legitimacy that are integral to the quality of coordinated action and crisis response. If the new arrangements are to improve the management of future disasters and crises, it is critical that these challenges be overcome.
}

88 - R. Opin. Jur., Fortaleza, ano 18, n. 29, p.77-97, set./dez. 2020 
ainda os dados epidemiológicos de cada membro, fazendo-o somente a partir do dia 14 de março, mediante dados publicados na respectiva página web. Fica, portanto, complexo afirmar que o Mecanismo de Proteção Civil, bem como os demais instrumentos, órgãos e programas para vigilância epidemiológica no âmbito europeu tenham funcionado de modo coerente, integrado e, principalmente, célere.

\section{O DEVER DE SOLIDARIEDADE PREVISTO NO TRATADO DE FUNCIONAMENTO DA UNIÃO EUROPEIA E O COVID-19: HÁ PARÂMETROS DE COMPARAÇÃO ENTRE “ANTES E DEPOIS”}

Uma vez analisados os mecanismos, os órgãos e as ações de combate a ameaças transfronteiriças no espaço integrado europeu, deve-se mencionar a questão da solidariedade prevista no artigo 222, numeral 3.1, do TFUE. Tal cláusula determina que, em caso de catástrofe de natureza humana ou natural ou, ainda, em caso de ataque terrorista, qualquer Estado-membro pode acionar os instrumentos de ajuda mútua, no marco da cooperação interinstitucional, tendo como base a atuação coordenada no seio da própria União.

De forma prática, ao acionar a solidariedade diante da necessidade delimitada pelo Estado, poderão ocorrer duas situações:

a) caso seja matéria que se vincula à política externa e de defesa comum, a Comissão e o Alto-Representante para a Política Exterior e a Política de Segurança (PESC) devem remeter um projeto de ação ao Conselho que, por unanimidade, determinará os meios para concretizá-lo, com auxílio do Comitê Político e de Segurança (CPS);

b) caso se trate de catástrofes de natureza animal ou humana, deverão ser acionados os meios determinados pela Declaração n. 37 ao Tratado de Lisboa, cujo conteúdo é bastante impreciso, já que cabe a cada Estado-membro responder conforme os meios que considere adequados, para cumprir o respectivo dever solidariedade para com o Estado afetado, combinado com o artigo 196 do TFUE sobre medidas de proteção civil.

O dever de solidariedade, portanto, encontrava-se já disposto no Tratado de Lisboa tanto em sua parte geral, quando se consideram como objetivo da União a cooperação, a solidariedade e a preservação do mercado comum (artigos $2^{\circ}$. e $3^{\circ}$.) - quanto em sua parte específica (Tratado de Funcionamento) ao tratar sobre o Mecanismo Europeu de Proteção Civil. Contudo, a Declaração mencionada deixava em aberto (norma programática) como deveria dar-se o procedimento de invocação e resposta tanto para o Estado afetado quanto para os Estados que deveriam prestar a assistência requerida.

No marco dessa discussão, visando a concretizar a alta flexibilidade conferida aos Estados em prestar ou não assistência, adotou-se a Decisão 2014/415/UE, em 24 de junho de 2014, que veio estabelecer e esclarecer a forma de atuação das instituições europeias e dos Estados.

No caso específico de defesa comum, por ocasião dos debates prévios à aprovação da Decisão, houve uma preocupação dirigida ao aspecto da correlação com a não intervenção, diferenciando a solidariedade da assistência mútua em se tratando de ataques terroristas e atos similares. Por ocasião dos ataques terroristas na França ocorridos em 13 de novembro de 2013, os debates foram novamente abertos, especialmente porque tal Estado recorreu à cláusula de assistência mútua e não à de solidariedade. 
Contudo, em se tratando de catástrofes como o caso do COVID-19 deve-se também alinhar a Decisão 2014/315/UE com as previsões contidas na já citada Decisão n. 1082/2013/EU (ameaças sanitárias transfronteiriças graves). A conjugação de ambas decisões deveria permitir aos Estados-membros e à União atuar de forma coordenada, em um marco regulatório que promova a contenção de riscos e/ou a mitigação de danos.

Portanto, uma vez invocada a cláusula de solidariedade (art. 4.1, Decisão 2014/315/UE), o Conselho deverá, por meio de sua Presidência, acionar o Mecanismo Integrado de Resposta Política a situações de crise (IRPC - sigla em inglês) e informar a todos os Estados-membros. Ao mesmo tempo, a Comissão e o Alto Representante da Política Exterior deverão tomar as seguintes medidas, segundo disposto no art. 5.2 da mencionada Decisão de 2014:

a) identificar todos os instrumentos relevantes da União que melhor possam contribuir para responder à crise, incluindo instrumentos e estruturas setoriais, operacionais, estratégicos ou financeiros, sempre ao abrigo do EUPCM. No caso específico do COVID-2019, levando em consideração a situação inicial da Itália, a União deveria ter tomado as providências de responder à solicitação cursada em 26 de fevereiro para fornecimento de equipamentos hospitalares (máscaras e aventais cirúrgicos);

b) identificar as capacidades militares que melhor possam contribuir para responder à crise, com o apoio da UE (no caso de ataques terroristas);

c) identificar e propor a utilização dos instrumentos e dos recursos da competência das agências da União que melhor possam contribuir para responder à crise. Neste sentido, conforme será comentado posteriormente, no caso do COVID2019, a União adotou uma série de medidas, incluindo o monitoramento pelo EDCD, a flexibilidade orçamentária, a restrição de livre trânsito visando a evitar a propagação e o contágio, entre outras;

d) indicar ao Conselho em que medida os instrumentos existentes são suficientes para ajudar o Estado-membro afetado na sequência da invocação da cláusula de solidariedade. Especificamente, no caso do COVID-2019, o pronunciamento feito pela Presidência da Comissão previu, inicialmente, ações paliativas buscando diminuir o contágio transfronteiriço, sem, contudo, anunciar medidas específicas voltadas, naquele momento (16 de março), para a Itália - Estado que havia invocado a cláusula.

Portanto, nota-se que, sob a perspectiva institucional, há duas instituições envolvidas:

1. Conselho Europeu: que deverá conduzir o processo de tomada de decisão estratégica da União, perante o qual se invocará a cláusula de solidariedade e se comunicará aos demais Estados-membros, funcionando como fonte de decisões políticas;

2. Comissão Europeia, cuja função será operacionalizar, concretizar e monitorar as ações tomadas, atuando como braço executivo e de gestão para que se possam efetivar os instrumentos adotados pela própria União.

Contudo, por razões óbvias, o Parlamento Europeu também deverá participar do processo decisório, uma vez que, conforme cada situação, a invocação da cláusula poderá demandar alteração em políticas da União, sejam exclusivas ou não, como foi o caso das orientações destinadas a modificar a aquisição de equipamentos por via de contratação pública. Nesse sentido, os atos legislativos que se fizerem necessários para a contenção da crise devem passar, a depender da matéria, pelo crivo e pela aprovação do Parlamento Europeu.

90 • R. Opin. Jur., Fortaleza, ano 18, n. 29, p.77-97, set./dez. 2020 
A pandemia criada pelo COVID-19, dado o alto grau de imprevisibilidade e da natureza extremamente atípica, demonstrou que, efetivamente, apesar de todo o arcabouço institucional e normativo da União, houve falha no sistema de resposta, resultando em um "delay” grave que, talvez, poderia ter minimizado a propagação tão célere no espaço europeu, como realmente ocorreu. Torna-se prematuro realizar um diagnóstico preciso da situação no atual contexto de instabilidade e desconhecimento (inclusive epidemiológico e sanitário sobre o vírus e os seus efeitos), todavia a própria União reconheceu a "demora" em responder ao pedido italiano, conforme carta publicada pela Presidente da Comissão Ursula von Leyen no Jornal La Repubblica em $1^{\circ}$ de abril:

É preciso reconhecer que, nos primeiros dias da crise, diante da necessidade de uma resposta européia comum, muitos pensaram apenas em seus próprios problemas domésticos. Eles não perceberam que só podemos derrotar essa pandemia juntos como uma União. Tal atitude foi prejudicial e poderia ter sido evitada (VON DER LEYEN, 2020, online). ${ }^{10}$

Poderiam os Estados ter, por intermédio da União Europeia, socorrido a Itália quando se fez uso da prerrogativa da invocação da cláusula? A cooperação e o auxílio poderiam ter evitado a alta propagação e o contágio, e mais as mortes que estão, diariamente, crescendo em todo o espaço europeu (Espanha, França, Holanda, Alemanha, entre outros)? São perguntas complexas que demandariam a análise de outros fatores, inclusive metajurídicos, para que se pudesse traçar um panorama definitivo sobre tais questões.

Já em situações anteriores, como no caso dos incêndios florestais ocorridos em vários Estados-membros, especialmente, durante os anos de 2017 e 2018, as instituições europeias já haviam alertado sobre a necessidade de agilizar, aperfeiçoar e estabelecer medidas mais efetivas de atuação, conforme se depreende da proposta legislativa feita pela Comissão solicitada pelo Conselho. Nessa proposta, depreende-se que:

A experiência recente tem demonstrado que a dependência de ofertas voluntárias de assistência mútua, coordenada e facilitada pelo Mecanismo da União, nem sempre asseguram a disponibilização de capacidades suficientes para dar resposta, de forma satisfatória, às necessidades básicas das pessoas afetadas por catástrofes, nem a salvaguarda adequada do ambiente e dos bens materiais. Tal é sobretudo evidente quando os Estados-Membros são simultaneamente afetados por catástrofes, que são recorrentes e inesperadas, sejam naturais ou de origem humana, e quando a capacidade coletiva é insuficiente. A fim de superar essas insuficiências e de lidar com os riscos emergentes, convém utilizar, de uma forma plenamente flexível, todos os instrumentos da União, nomeadamente através da promoção da participação ativa da sociedade civil. (UNIÃO EUROPÉIA, 2019, p. 4, grifo nosso).

E continua a Comissão alertando no texto da proposta que

Afigura-se necessário simplificar, racionalizar e aumentar a flexibilidade dos procedimentos do Mecanismo da União para garantir que os EstadosMembros possam ter acesso rápido à assistência e às capacidades

\footnotetext{
${ }^{10}$ No original: Bisogna riconoscere che nei primi giorni della crisi, di fronte al bisogno di una risposta comune europea, in troppi hanno pensato solo ai problemi di casa propria. Non si rendevano conto che possiamo sconfiggere questa pandemia solo insieme, come Unione. È stato un comportamento dannoso e che poteva essere evitato. Lettera di Ursula von der Leyen, presidente della Commissione europea a Repubblica.
} 
necessárias para responder, o mais rápida e eficientemente possível, a catástrofes naturais ou de origem humana (UNIÃO EUROPÉIA, 2019, p. 12).

$\mathrm{Na}$ referida proposta, há ainda importantes elementos de natureza financeira destinados a reforçar não só o EUCPM, como também concretizar todos os procedimentos para a instalação do rescUE. Portanto, em situações anteriores (incêndios florestais de irradiação transfronteiriça), já se configuravam os "gargalos" que poderiam resultar na ausência de uma gestão eficiente e coordenada por parte da União e também dos Estadosmembros.

É incontestável, não obstante, que a inércia dos Estados e da própria União e o "emaranhado" burocrático no qual se escusaram tanto um como outro para dar uma resposta rápida provocou uma crise sem precedentes na construção do ideal integracionista europeu e pode, no futuro, macular todo o esforço feito ao longo dos últimos 70 (setenta) anos desde a entrada em vigor do Tratado CECA.

\section{A POSSIBILIDADE DE NOVAS MEDIDAS FRENTE À ESPECIFICIDADE DO COVID-19 E O DEVER DE SOLIDARIEDADE}

Solidariedade no enfrentamento do COVID-19 significa ir além da disposição formal de competência e dos mecanismos previamente estabelecidos e já analisados. A guerra comunitária contra um inimigo invisível e imprevisível forçará suas instituições a agirem com rapidez e comprometimento na construção de uma solução comum.

A ação europeia será determinante para a tomada de decisão de outros Estados, assim como para o desenvolvimento de instrumentos globais, tendo em vista que a propagação do vírus já excede as fronteiras nacionais e regionais.

A formação do Estado passa por três elementos, são eles: população, território e governo/soberania. Nesse aspecto, o elemento central é o humano representado por uma população coagida e confinada, que espera, por parte dos Estados e da União Europeia, uma solução firme, coerente e conjunta para a crise vivenciada.

$\mathrm{Na}$ perspectiva de enfrentamento do COVID-19, foi estabelecida uma série de decisões, em especial a partir do dia 16 de março de 2020 (UNIÃO EUROPÉIA, 2020b), buscando ressaltar a necessidade de solidariedade europeia com a adoção de medidas econômicas, orçamentarias e fiscais, principalmente com a flexibilidade do Pacto de Estabilidade e Convergência. Afinal, a crise trará repercussões econômicas que deverão ser enfrentadas com o apoio de um plano de ajuda mútua (financeira, política, jurídica e social) da União Europeia.

Partindo do discurso da Presidente da Comissão Europeia, Ursula von der Leyen ${ }^{11}$, no dia 16 de março de 2020, determinando-se a restrição temporária de circulação (viagens) por 30 (trinta) dias e a criação de sistemas prioritários para a manutenção de circulação de mercadorias que possam abastecer os Estados e, consequentemente, evitar a escassez de medicamentos, alimentos e bens de primeira necessidade, iniciaram-se efetivamente as medidas para a contenção do vírus. Portanto, este foi o momento crucial para a compreensão do acionamento de medidas mais drásticas e mais profundas no combate à crise.

\footnotetext{
${ }^{11}$ Disponível em: https://mobile.twitter.com/vonderleyen/status/1239568170152857607?s=09. Acesso em: 16 mar. 2020.
}

92 - R. Opin. Jur., Fortaleza, ano 18, n. 29, p.77-97, set./dez. 2020 
A solidariedade deve ser um ponto-chave na atuação coordenada, liderada, de forma ainda mais decisiva, pelas instituições europeias e pelos Estados-membros, ainda que respeitadas as especificidades de cada um deles. Esta solidariedade se reveste de natureza obrigatória segundo a cláusula inserida no artigo 222, numeral 3.1, do TFUE, resultando não só na concepção de um ajuda mútua entre os Estados, mas também em esforços coletivos para o combate e a mitigação da crise sanitária transfronteiriça.

Nesse sentido, observa-se a necessidade de medidas a serem tomadas pelos Estados de modo a reforçar a atuação da União e dos seus respectivos membros, bem como as medidas que deverão ser coordenadas no marco da cláusula de solidariedade.

Em relação aos Estados, tomando-se como parâmetros os documentos oficiais da própria União Europeia (já citados anteriormente), foram adotadas as seguintes linhas de ação:

a) trânsito de pessoas entre os membros e países extrazona: os Estados devem propiciar e solicitar informações claras e confiáveis aos viajantes sobre as formas de contágio e cuidados médicos adequados;

b) ameaças sanitárias transfronteiriças graves, conforme previsão da Decisão n. 1082/2013/UE: adotar medidas de coordenação estreita e reforçada, principalmente nas viagens intrazona, visando a incrementar o monitoramento, a vigilância e o compartilhamento de informações sobre a evolução do COVID2019 no interior de cada Estado, acionando os mecanismos e as estruturas para tal fim (EUCPM, por exemplo);

c) solidariedade e cooperação nacional, regional e internacional: criar orientações comuns em matéria do potencial de transmissão, diagnóstico, meios de gestão e tratamento hospitalar e sanitário, otimização da utilização de antivirais, entre outros;

d) informações precisas para combater a falsidade e a ausência de informações: monitorar e divulgar em todos os meios possíveis ações cientificamente comprovadas, evitando a disseminação de fake news;

e) indústria e centros de pesquisa, universidades e investigação: cooperar e reforçar a ação conjunta, buscando facilitar o desenvolvimento de uma vacina piloto contra o Covid19 e o desenvolvimento de meios de diagnóstico e de antivirais.

Por parte da Comissão, foram adotadas medidas tendentes a facilitar, bem como a incrementar o compartilhamento de informações e a cooperação entre os Estadosmembros, em especial no que se refere ao tratamento e à gestão dos riscos e das contramedidas tomadas em relação ao COVID-19. Também, há uma série de medidas em curso para as próximas fases do surto, visando a minimizar os impactos financeiros, sociais, sanitários e, assim, a apoiar fortemente a cooperação entre os Estados-membros.

A Comissão estabeleceu, ainda, como ação necessária, a flexibilização do marco regulatório orçamentário e dos programas de financiamento, bem como de contratação pública para aquisição de bens e equipamentos hospitalares e sanitários (conforme comentado alhures), visando a atuar de forma coordenada com os Estados-membros. Uma das principais preocupações manifestadas nas comunicações, nos pronunciamentos e nos documentos oficiais emitidos pela Comissão ${ }^{12}$ refere-se a uma ação conjunta de medidas relacionadas ao isolamento, à quarentena e à limitação dos contatos sociais, com base na dinâmica atual da situação epidemiológica, em conformidade com os pareceres científicos

\footnotetext{
${ }^{12}$ Vide, a título de exemplo, a página sobre as medidas tomadas pela Comissão Europeia em relação ao COVID-19 disponível em https://ec.europa.eu/info/live-work-travel-eu/health/coronavirusresponse/public-health_en. Acesso em: 19 mar. 2020.
} 
do ECDC e da OMS, bem como à disponibilidade de medicamentos na UE e à segurança das cadeias de abastecimento de bens de consumo.

Este é, justamente, um aspecto importante que demonstra a dissonância na distribuição de competências comuns, em especial quando se trata de matéria de saúde pública (sendo, como se viu, mera competência de apoio e/ou complementar), pois cada Estado adotou, em maior ou menor medida, ações específicas de combate à propagação do vírus, de forma unilateral, sem que houvesse um diálogo concertado entre todos os membros, dificultando, assim, uma ação efetivamente conjunta.

Também a resposta tardia das instituições europeias em relação à situação da Itália, amplamente divulgada nos meios de comunicação ${ }^{13}$, minou a confiança dos atores nacionais (públicos e privados) nos instrumentos de gestão de crise que a própria União apresenta como elementos fundamentais para a proteção de seus cidadãos. Em momentos de crise, pode-se afirmar, sem dúvida, que o papel das instituições representa um porto seguro para que a comunidade possa sentir-se realmente protegida e avalizada por um sistema comum que se diz coerente, firme e eficiente.

\section{CONCLUSÃO}

A crise causada pela pandemia global que se instalou e se propagou rapidamente pelo território europeu demonstrou como, em momentos de extrema necessidade, os Estados-membros da União Europeia são solapados por uma catástrofe de natureza sanitária imprevisivel e altamente devastadora, haja vista o número de infectados e de mortes causadas, os instrumentos existentes não se mostraram suficientes para gerar uma resposta célere, coordenada e eficaz.

No presente artigo, abordamos quais são os instrumentos criados no marco da UE, que poderiam ser utilizados para o enfrentamento da crise gerada pelo COVID-19. Nota-se que há um sistema institucional, legal, de gestão e operacional que já fora anteriormente acionado, mas apresenta falhas importantes quando os Estados se defrontam, simultaneamente, com problemas idênticos.

A análise perpassa, necessariamente, pela compreensão da competência atribuída pelos Estados à União, como organização supranacional, cujos valores e objetivos expressam as vontades desses mesmos Estados na construção de um sistema institucional e normativo próprio, sob uma perspectiva de coordenação e não de subordinação.

Portanto, a primeira reflexão deve referir-se ao modo como a União poderia atuar, com a adoção de medidas concretas, a partir da atribuição de competências que lhe foram atribuídas pelos entes estatais, considerando-se que deverá haver respeito ao regramento vinculado aos seus objetivos e valores, notadamente o mercado comum - e suas quatro liberdades fundamentais - ao passo que a política de saúde se encontra sob a égide do Estado. Isso significa uma equação complexa e o sopesamento do equilibrio entre o exercício de poderes pela União, no marco do direito europeu (Tratados e demais atos normativos), e a parcela de poder que, de forma gradual, restou ao Estado, mesmo assim, pensando-se na possibilidade de "avocação" que pode ser feita pela União (conforme analisado) no quadro das competências implícitas e subsidiárias.

\footnotetext{
${ }^{13}$ Vide, por todos, https://foreignpolicy.com/2020/03/14/coronavirus-eu-abandoning-italy-china-aid/. Acesso em: 22 mar. 2020.
}

94 - R. Opin. Jur., Fortaleza, ano 18, n. 29, p.77-97, set./dez. 2020 
A tal efeito, a competência para decidir sobre matéria de política de saúde poderia ser exercida pela União, de forma a concretizar os instrumentos de contenção de catástrofes que se encontram regulados também no âmbito do direito europeu.

Há de se observar, ainda, que a questão competencial é deveras complexa em um sistema organizacional cujas decisões dependem de acordos e negociações a serem realizadas conjuntamente por 27 Estados, ainda que em uma moldura supranacional previamente estabelecida e desenvolvida durante o período de construção da Europa integrada.

Para além das discussões políticas - tendo sempre os Estados como epicentro e alvo delas - e também jurídicas (a partir da ampla regulação já adotada, que foi tratada no presente artigo), o fato é que se podem constatar, ainda que de modo preliminar, repise-se, dada a imprevisibilidade e o estado instável em que se vive, dois aspectos importantes:

a) a necessidade de reforçar os mecanismos de proteção civil, evitando que as decisões sejam tomadas com "atraso" e sem apresentar soluções efetivas, dado que a demora pode representar um fator crucial baseado no tempo de resposta;

b) a solidariedade, como dever de cooperação não só manifestada nos Tratados fundacionais, mas também na regência de toda a normativa europeia, deve pautar-se em ações concretas que venham a especificar em que medida cada Estado pode cooperar com os demais, sempre sob o manto da União. Essa organização, cujo valor fundamental se refere a uma associação interestatal em um esquema, até então, inédito, baseia-se, justamente, nesse elemento de solidariedade entre os povos. Chama-se dever porque não poderia haver recusa ou inércia diante da invocação feita por um de seus participantes.

Finalmente, deveria a União Europeia demonstrar sua força, concretizar seu lema (Unida na diversidade), ressaltar como a integração entre os Estados, os povos e as culturas serve não só para o crescimento econômico, mas também para o bem-estar, a dignidade humana, a preservação da vida... Espera-se que os esforços empreendidos tão valiosamente por Jean Monnet e Robert Schumann não tenham sido em vão e, acima de tudo, não sejam destruídos pelo tsumani sanitário no qual a Europa e o mundo se encontram. Espera-se, principalmente, que se possa acreditar na UE como referencial de integração cooperativa e dialógica, em um espaço de auxílio e cooperação mútuos. Para isso, tornam-se urgentes ações mais concretas e efetivas baseadas na solidariedade entre os Estados e na confiança dada à própria União.

\section{REFERÊNCIAS}

BOUTAYEB, Chahira. Droit institutionnel de l'Union européenne: Institutions, ordre juridique, contentieux. 5th ed. Paris: L.G.DJ, 2018.

COMISÍON EUROPEA. Protección Civil y Operaciones de Ayuda Humanitaria

Europeas: Protección Civil de la UE. 2018. Disponível em: https://ec.europa.eu/echo/files/aid/countries/factsheets/thematic/civil_protection_es.pdf . Acesso em: 22 mar. 2020.

DEL POZO, Carlos Francisco Molina; MATA DIZ, Jamile Bergamaschine Mata. La distribución de competencias en el nuevo diseño de la Unión Europea: del Acta Única Europea al Tratado de Lisboa. Revista da Facultad de Derecho y Ciencias Políticas, v. 43, n. 118, p. 15-59, enero/jun. 2013.

EUROPA. Tribunal de Cuentas Europeu. Informe Especial n. 33 - Mecanismo de Protección Civil de la Unión: la coordinación de las respuestas a las catástrofes fuera del 
territorio de la UE ha sido eficaz en términos generales. 2016. Disponível em: https://www.eca.europa.eu/Lists/ECADocuments/SR16_33/SR_DISASTER_RESPONS E_ES.pdf. Acesso em: 28 mar. 2020.

EUROPEAN CENTRE FOR DISEASE PREVENTION AND CONTROL. COVID-19 situation update for the EU/EEA and the UK, as of 18 june 2020. 2020. Disponivel em: https://www.ecdc.europa.eu/en/cases-2019-ncov-eueea. Acesso em: 6 abr. 2020.

EUROPEAN COMMISSION. Public health. Disponivel em: https://ec.europa.eu/info/live-work-travel-eu/health/coronavirus-response/publichealth_en. Acesso em: 1 abr. 2020.

LENARCIC, Janis. EXIGE medidas específicas... In: CORONAVÍRUS lenárico: países da UE assistem e aprendem com a Itália. Askanews, 6 mar. 2020. Disponível em: https://www.askanews.it/esteri/2020/03/06/coronavirus-lenarcic-paesi-ue-guardino-eimparino-da-italia-pn_20200306_00234/. Acesso em: 6 abr. 2020.

MAGNOLI, Demétrio. União Europeia: história e geopolítica. 5. ed. São Paulo: Moderna, 1995.

MATA DIZ, Jamile Bergamaschine; CARNEIRO, Caio A. de Castro. (Re)visitando o primado das normas de Direito Europeu: a evolução histórica da primazia e seus primeiros desdobramentos jurisprudenciais. Revista Jurídica, Curitiba, v. 4, n. 49, p. 255-284, 2017.

MATA DIZ, Jamile Bergamaschine; JAEGER JÚNIOR, Augusto. Por uma teoria jurídica da integração regional: a inter-relação direito interno, direito internacional público e direito da integração. Revista de Direito Internacional, Brasília, v. 12, n. 2, p. 237-360, 2015.

PROGRAMME OF CROATIAN PRESIDENCY OF THE COUNCIL OF THE EUROPEANUNION. A strong Europe in a world of challenges. 2020. Disponível em: https://vlada.gov.hr/UserDocsImages/Vijesti/2019/12\%20prosinac/31\%20prosinca/web _FINAL_PROGRAMME_EN_FINAL.pdf. Acesso em: 28 mar. 2020.

UNIÃO EUROPÉIA. Regulamento (CE) n. ${ }^{\circ}$ 851/2004 do Parlamento Europeu e do Conselho de 21 de Abril de 2004 que cria um Centro Europeu de Prevenção e Controlo das Doenças. Jornal Oficial da União Europeia, 30 abr. 2004. Disponível em: https://eurlex.europa.eu/legalcontent/PT/TXT/HTML/?uri=CELEX:32004R0851\&from=PT\#d1e255-1-1. Acesso em: 27 mar. 2020.

UNIÃO EUROPÉIA. Decisão n. ${ }^{\circ}$ 1313/2013/UE do Parlamento Europeu e do Conselho de 17 de dezembro de 2013 relativa a um Mecanismo de Proteção Civil da União Europeia. Jornal Oficial da União Europeia, 20 dez. 2013. Disponível em: https://eurlex.europa.eu/legal-content/PT/TXT/PDF/?uri=CELEX:32013D1313\& from=EN. Acesso em: 21 mar. 2020.

UNIÃO EUROPÉIA. Parlamento Europeu e Conselho. 20170309 (COD) - PE-CONS 90/18PROCIV 96 - JAI 1333 - COHAFA 118 - FIN 1044 - CODEC 2413. Bruxelas, 20 de fevereiro de 2019. Disponível em: https://data.consilium.europa.eu/doc/document/PE90-2018-INIT/pt/pdf. Acesso em: 25 mar. 2020.

UNIÃO EUROPÉIA. Comunicação da Comissão. Orientações da Comissão Europeia sobre a utilização do quadro em matéria de contratos públicos na situação de emergência relacionada com a crise da COVID-19 (2020/C 108 I/01). Jornal Oficial da União Europeia, 1 abr. 2020a. Disponível em: https://eur-lex.europa.eu/legal96 - R. Opin. Jur., Fortaleza, ano 18, n. 29, p.77-97, set./dez. 2020 
content/PT/TXT/HTML/?uri=CELEX:52020XC0401(05)\&from=EN. Acesso em: 1 abr. 2020.

UNIÃO EUROPÉIA. Conclusões do conselho sobre o COVID-19. Jornal Oficial da União Europeia, 20 fev. 2020b. Disponível em: https://eur-lex.europa.eu/legalcontent/PT/TXT/HTML/?uri=CELEX:52020XG0220(01)\&from=EN. Acesso em: 1 mar. 2020.

VON DER LEYEN, Di Ursula. Ursula von der Leyen: "Scusateci, ora la Ue è con voi". Jornal La Repubblica, 1 apr. 2020. Disponível em: https://rep.repubblica.it/pwa/commento/2020/04/01/news/europa_ursula_von_der_ley en_bruxelles_scusateci_ora_la_ue_e_con_voi-252912437/?ref=nrct-1. Acesso em: 2 abr. 2020.

WIDMALM, Sten; PARKER, Charles F.; PERSSON, Thomas. Civil protection cooperation in the European Union: how trust and administrative culture matter for crisis management. Basingstoke: Palgrave, 2019.

\section{NOTA}

Declaro para os devidos fins que o artigo intitulado "A solidariedade como fundamento para o enfrentamento do COVID-19 na União Europeia”, submetido à Revista Opinião Jurídica representa fruto direto das atividades da Rede de Pesquisa "Integração, Estado e Governança" tendo as respectivas autoras (membros permanentes da referida Rede) realizado concomitantemente as tarefas de planejamento, execução e revisão do mencionado artigo da seguinte forma: i) Jamile Bergamaschine Mata Diz: desenvolveu de forma mais específica a parte relativa às competências da União Europeia, bem como os procedimentos para invocar a cláusula de solidariedade; ii) Alice Rocha da Silva: desenvolveu de forma mais específica a parte da análise jurídica que embasa a cláusula de solidariedade, bem como os instrumentos e mecanismos de proteção civil; iii) Elizabeth Accioly Rodrigues da Costa: desenvolveu de forma específica a parte da trajetória e marco regulador da atuação da União Europeia e também da linha do tempo de resposta institucional. Reafirma-se que todas as autoras trabalharam na formulação do problema, hipótese e das conclusões.

\section{Como citar este documento:}

DIZ, Jamile Bergamaschine Mata; COSTA, Elizabeth Accioly Rodrigues; SILVA, Alice Rocha da. A Solidariedade como fundamento para o enfrentamento do Covid-19 na União Europeia. Revista Opinião Jurídica, Fortaleza, v. 18, n, 29, p. 77-97, set./dez. 2020. 